\title{
ROCK1 Translocates From Non-Caveolar to Caveolar Regions Upon KCI Stimulation in Airway Smooth Muscle
}

\author{
B. SOMMER ${ }^{1}$, L. M. MONTAÑO ${ }^{2}$, J. CHÁVEZ ${ }^{1}$, V. CARBAJAL ${ }^{1}$, L. M. GARCÍA- \\ HERNANDEZ ${ }^{2}$, C. IRLES ${ }^{4}$, A. M. JIMÉNEZ-GARDUÑO ${ }^{3}$, A. ORTEGA $^{3}$
}

${ }^{1}$ Department of Bronchial Hyperreactivity Research, National Institute of Respiratory Diseases, Mexico City, Mexico, ${ }^{2}$ Department of Pharmacology, Faculty of Medicine, National Autonomous University of Mexico, Mexico City, Mexico, ${ }^{3}$ Department of Biochemistry, Faculty of Medicine, National Autonomous University of Mexico, Mexico City, Mexico, ${ }^{4}$ Department of Physiology, Faculty of Medicine, National Autonomous University of Mexico, Mexico City, Mexico

Received March 25, 2013

Accepted September 17, 2013

On-line January 8, 2014

\section{Summary}

Airway smooth muscle (ASM) membrane depolarization through $\mathrm{KCl}$ opens L-type voltage dependent $\mathrm{Ca}^{2+}$ channels $\left(\mathrm{Ca}_{\mathrm{v}} 1.2\right)$; its opening was considered the cause of $\mathrm{KCl}$ contraction. This substance is used to bypass intracellular second messenger pathways. It is now clear that $\mathrm{KCl}$ also activates RhoA/Rho kinase (ROCK) pathway. ROCK isoforms are characterized as ROCK1 and ROCK2. Because ROCK1 seems the most abundant isotype in lung, we studied its participation in $\mathrm{KCl}$ stimulated bovine ASM. With methyl- $\beta$-cyclodextrin (MBCD) we disrupted caveolae, a membrane compartment considered as the RhoA/ROCK assembly site, and found that $\mathrm{KCl}$ contraction was reduced to the same extent ( $\sim 26 \%)$ as Y-27632 (ROCK inhibitor) treated tissues. We confirmed that $\mathrm{KCl}$ induces ROCK activation and this effect was annulled by $\mathrm{Y}-27632$ or $\mathrm{M} \beta C D$. In isolated plasmalemma, ROCK1 was localized in non-caveolar membrane fractions in Western blots from control tissues, but it transferred to caveolae in samples from tissues stimulated with $\mathrm{KCl}$. $\mathrm{Ca}_{\mathrm{v}} 1.2$ was found at the non-caveolar membrane fractions in control and $M \beta C D$ treated tissues. In $M \beta C D$ treated tissues stimulated with $\mathrm{KCl}$, contraction was abolished by nifedipine; only the response to $\mathrm{Ca}_{\mathrm{v}} 1.2$ opening remained as the ROCK component disappeared. Our results show that, in ASM, the $\mathrm{KCl}$ contraction involves the translocation of ROCK1 from noncaveolar to caveolar regions and that the proper physiological response depends on this translocation.

\section{Key words}

Bovine airway smooth muscle • Rho-kinase1 • Caveolae • L-type $\mathrm{Ca}^{2+}$ channels

\section{Corresponding author}

B. Sommer, Bronchial Hyperreactivity Research Department, National Institute of Respiratory Diseases, Calzada de Tlalpan 4502, Mexico City, D.F. CP 14080, Mexico. Fax: (52-55)56665868. E-mail: bsommerc@hotmail.com

\section{Introduction}

For a long time, $\mathrm{KCl}$ induced airway smooth muscle (ASM) contraction has been considered to be developed solely by $\mathrm{Ca}^{2+}$ influx through L-type voltagedependent $\mathrm{Ca}^{2+}$ channels $\left(\mathrm{Ca}_{\mathrm{v}} 1.2\right)$. In vascular smooth muscle, it has been demonstrated that $\mathrm{KCl}$ causes $\mathrm{Ca}^{2+}$ sensitization via Rho-activated kinase (ROCK) activation (Mita et al. 2002, Urban et al. 2003). $\mathrm{Ca}^{2+}$ sensitization involves monomeric $\mathrm{G}$ protein RhoA and its downstream effector, ROCK, responsible of phosphorylating myosin light chain phosphatase (MLCP) on its targeting subunit, diminishing its activity, and therefore favoring contraction without detectable changes in $\left[\mathrm{Ca}^{2+}\right] \mathrm{i}$ (Somlyo and Somlyo 2003). In ASM, RhoA translocation to the membrane is indispensable for the signaling pathway activation (RhoA/ROCK), and it is thought to be depolarization and $\mathrm{Ca}_{\mathrm{v}} 1.2$ dependent (Janssen et al. 2012). Additionally, it is known that $\mathrm{KCl}$ stimulation 
promotes cytosolic ROCK translocation to specialized membrane domains called caveolae in vascular smooth muscle (Urban 2003). However, Nuno et al. (2012) published recently that, in mice aortic tissues, ROCK moves from caveolar to non-caveolar regions after 5-HT stimulation, showing that ROCK translocation develops in the membrane domains and not only from the cytosol to caveolae. ROCK isoforms have been characterized as ROCK1 and ROCK2. It has been documented that their distribution is tissue related: isotype 1 is abundant in lung, liver, spleen, kidney and testis, whereas isotype 2 is present mainly in heart, vascular and brain (Noma et al. 2006, Nuno et al. 2012). Therefore, we found it noteworthy to define if ROCK1 localization in ASM membrane domains is related to its function during depolarization-induced contraction.

By the other hand, $\mathrm{Ca}_{\mathrm{v}} 1.2$ localization in lipid rafts has been well documented, and their proper functionality seems independent of caveolar integrity. In rat cerebral artery, methyl- $\beta$-cyclodextrin $(\mathrm{M} \beta \mathrm{CD})$ treatment, a pharmacological agent commonly used to remove membrane cholesterol and disrupt caveolae (Sommer et al. 2009), did not modify the $\mathrm{Ca}_{\mathrm{v}} 1.2$ currents (Löhn et al. 2000). In this same context, using tail artery from rats or rat ureter smooth muscle, $\mathrm{KCl}$ tonic responses were not altered by caveolae disruption after MBCD treatment (Dreja et al. 2002, Babiychuk et al. 2004). Furthermore, $\mathrm{Ca}_{\mathrm{v}} 1.2$ showed partial colocalization with caveolin-1 (Cav-1) at the cell membrane of the intestinal smooth muscle cells, interstitial cells of Cajal, and lower esophageal sphincter and skeletal muscle cells of mouse (Cho and Daniel 2005). In canine airway smooth muscle, Darby et al. (2000) found that $\mathrm{Ca}_{\mathrm{v}} 1.2$ are enriched in caveolae, but proposed that it is more likely that they are located throughout the plasma membrane.

In the present work we explored the possibility that $\mathrm{KCl}$ activates RhoA/ROCK pathway and promotes ROCK1 translocation from non-caveolar to caveolar membrane region. We also studied the membrane localization of the $\mathrm{Ca}_{\mathrm{v}} 1.2$ in airway smooth muscle.

\section{Materials and Methods}

\section{Organ baths experiments}

Bovine tracheal tissues were obtained from a local slaughterhouse and immersed in ice-cold Krebs solution for its transportation to the laboratory. Tissues were dissected free of cartilage, epithelium and connective tissue, and smooth muscle strips $(2-2.5 \mathrm{~mm}$ wide, $5 \mathrm{~mm}$ long) were cut and suspended in $5 \mathrm{ml}$ organ baths containing Krebs solution (in $\mathrm{mM}$ ): $118 \mathrm{NaCl}$, $25 \mathrm{NaHCO}_{3}, 4.6 \mathrm{KCl}, 1.2 \mathrm{KH}_{2} \mathrm{PO}_{4}, 1.2 \mathrm{MgSO}_{4}$, 11 glucose, and $2 \mathrm{CaCl}_{2}$. Preparations were maintained at $37{ }^{\circ} \mathrm{C}$ and bubbled with $5 \% \mathrm{CO}_{2}$ in oxygen at $\mathrm{pH}$ 7.4. Tissues were attached to an isometric force transducer (model FT03; Grass Instruments, West Warwick, RI, USA) connected to a system of signal conditioner (CyberAmp 380, Axon Instruments, Foster City, CA, USA) plus an analog-digital interface (Digidata 1200A; Axon). Recordings were stored in a microcomputer and analyzed using data acquisition and analysis software (AxoScope version 9.0; Axon). Preparations were equilibrated for 30 min under a resting tension of 1-1.5 $\mathrm{g}$ before testing. Tissues were then stimulated three times with $60 \mathrm{mM} \mathrm{KCl}$ (lasting $20 \mathrm{~min}$ each) until maximum stable responses were obtained. Tissues were washed 3 times with Krebs solution and, once the basal tone was reached, a fourth $\mathrm{KCl}$ stimulation was done. Afterwards, some tissues were incubated with (+)-(R)-trans-4-(1aminoethyl)-N-(4-pyridyl) cyclohexane carboxamide $(\mathrm{Y}-27632,10 \mu \mathrm{M})$, a ROCK inhibitor, and stimulated again with $\mathrm{KCl}$. In some experiments, tissues were contracted with $\mathrm{KCl}$ and during the maximal contraction responses $1 \mu \mathrm{M}$ nifedipine was added, followed later by $10 \mu \mathrm{M} \mathrm{Y}-27632$; in this context, similar experiments were carried out but adding Y-27632 first. In other set of experiments tissues were preincubated with $40 \mathrm{mM}$ methyl- $\beta$-cyclodextrin $(\mathrm{M} \beta \mathrm{CD})$ for $3 \mathrm{~h}$, washed and then stimulated with $60 \mathrm{mM} \mathrm{KCl}$. Other tissues, after the incubation with $\mathrm{M} \beta \mathrm{CD}$, were stimulated with $\mathrm{KCl}$ and when the maximum response was reached, nifedipine was added. In order to verify a possible additive effect among $\mathrm{M} \beta \mathrm{CD}$ and Y-27632, bovine tracheal smooth muscle was incubated with both drugs and stimulated with $\mathrm{KCl}$. Control tissues without $\mathrm{M} \beta \mathrm{CD}$ were stimulated with $\mathrm{KCl}$ after $3 \mathrm{~h}$.

\section{Isolation of plasmalemma preparation}

Microsomal membranes were obtained from previously frozen bovine tracheal smooth muscle stimulated or not with $60 \mathrm{mM} \mathrm{KCl}$. Another set of tissues was treated with $40 \mathrm{mM} \mathrm{M} \beta C D$ for $3 \mathrm{~h}$. Plasmalemma was isolated from the microsomal fraction by differential centrifugation and a discontinuous sucrose gradient in the absence of any reducing agent in a buffer medium containing in mM: 20 tris-malate, $100 \mathrm{KCl}, 300$ sucrose $(10 \%), \mathrm{pH}$ 7.0. A first sucrose gradient of $24,35,43$ and 
$55 \%$ was centrifuged at 95,200g (Beckman SW28, CA, USA) for $2 \mathrm{~h}$, to separate the plasmalemma. We found that the interface between 10 to $24 \%$ contains the highest proportion of Cav-1 and the $\mathrm{Ca}_{\mathrm{v}} 1.2$, molecular markers for plasma membrane. This fraction was washed in a buffer containing: $20 \mathrm{mM}$ Tris-maleate $\mathrm{pH} 7.0$ and centrifuged at $180,000 \mathrm{~g}$ (Beckman 45Ti, CA, USA)/ $45 \mathrm{~min}$. The collected membranes were treated with a solution containing $20 \mathrm{mM}$ Tris-maleate and $1 \%$ Triton X-100 (Calbiochem, Darmstadt, Germany), pH 7.0, at $4{ }^{\circ} \mathrm{C}$ for $30 \mathrm{~min}$. The membranes were diluted $1: 1$ with a solution containing $20 \mathrm{mM}$ Tris-maleate, $80 \%$ sucrose to give a final sucrose concentration of $40 \%, \mathrm{pH} 7.0$. Triton X-100 treated plasmalemma was placed at the bottom of a second gradient: 40, 30 and 5\%. This gradient was centrifuged at 250,000g (BeckmanSW55T1, CA, USA) overnight, and afterwards nine fraction of equal volume $(0.5 \mathrm{ml})$ were collected.

Caveolar and non-caveolar membrane fractions were then recognized following a modification of the methods described previously (Blank et al. 2002). Lowdensity fractions ( 1 to 5), designated as membrane caveolar fractions, are not soluble with Triton X-100 and high-density fractions (6 to 9), called non-caveolar membrane fractions, are enriched in Triton X-100. To corroborate that the low-density fractions correspond to lipid rafts, the expression of GM1 (a characteristic caveolar gangleoside, Parton 1994) was evaluated. From each fraction (9 in total) $2 \mu \mathrm{l}$ were submitted to a dot blot in a nitrocellulose membrane that was blocked with $1 \%$ non fat dry milk in TBS tween (Tween 20, $0.1 \%$, TBST) for $1 \mathrm{~h}$. Afterwards, the membrane was incubated with cholera toxin B conjugated to FITC (1:10,000, Sigma). Dots were revealed with an ECLTM chemiluminescence kit and photographic paper (Amersham Hyperfil, ECL, Cat. 28-9068-35, Buckinghamshire, UK). Caveolar fractions 3-4 and non-caveolar fractions 8-9 respectively, were pooled as published elsewhere (Sommer et al. 2009). Total protein content was determined using Coomassie Plus Protein Assay Reagent (Pierce, Rockford, IL USA) with BSA as the standard. Samples were then adjusted to a protein content of $10 \mu \mathrm{g}$ and boiled for $2 \mathrm{~min}$. These samples were loaded in different lanes of an $8 \%$ SDS-polyacrylamide gel and subjected to electrophoresis. Afterwards, proteins were transferred to a nitrocellulose membrane and blocked with $1 \%$ non fat dry milk in TBST for $1 \mathrm{~h}$. Membranes were incubated overnight at $4{ }^{\circ} \mathrm{C}$ with $1: 1000$ mouse anti-Cav-1 (monoclonal, cat \# 610406, Becton Dikinson, CA, USA),
1:500 rabbit anti-Ca 1.2 (cat \# ACC-003, Alomone, Jerusalem, Israel) or 1:500 rabbit anti-ROCK1 (cat \# ab45171, Abcam, MA, USA). We used ROCK1 antibody since its mRNA is preferentially expressed in lung, whereas ROCK2 mRNA is highly expressed in the heart and brain (Noma et al. 2006). The secondary antibody (HRP conjugated goat anti-mouse, Amersham Biosciences, Buckinghamshire, UK; or anti-rabbit IgG, Millipore-Upstate, CA, USA; 1:1000), was incubated during $1.5 \mathrm{~h}$, at room temperature. Immunoblots were developed using an enhanced chemiluminescent reactant (LumiGLO; Cell Signaling, MA, USA) and sheets of photographic paper (Amersham Hyperfilm, ECL, Cat. 289068-35).

To confirm that proteins were properly transferred to the nitrocellulose membrane, Ponceau red was added and the membranes were gently shaken for 15 min until the bands were seen.

To evaluate the presence of ROCK $1, \mathrm{Ca}_{\mathrm{v}} 1.2$ and Cav-1 in caveolar and non-caveolar fractions, a densitometric analysis was carried out using ImageJ NIH software (http://rsb.info.nih.gov/ij/).

The research protocol was approved by the Scientific and Ethical committee from the National Institute of Respiratory Diseases.

\section{Assay for ROCK activity}

ROCK mediated phosphorylation of the myosin phosphatase targeting subunit (MYPT1) by $60 \mathrm{mM} \mathrm{KCl}$, $10 \mu \mathrm{M}$ Y $-27632+60 \mathrm{mM} \mathrm{KCl}$ or $40 \mathrm{mM} \mathrm{M \beta CD}+$ $60 \mathrm{mM} \mathrm{KCl}$ was determined (Sommer et al. 2009). Briefly, bovine tracheal smooth muscle strips were placed in organ baths and submitted to the previously described protocol. Afterwards, they were collected and frozen in liquid nitrogen. Tissues were homogenized (Polytron PT 1200 E, Kinematica, Luzern, Switzerland) in $500 \mu \mathrm{l}$ lysis solution containing $50 \mathrm{mM}$ Tris- $\mathrm{HCl}, \mathrm{pH} 7.5,0.1 \mathrm{mM}$ EDTA, $0.1 \mathrm{mM}$ EGTA, $750 \mathrm{mM} \mathrm{NaCl}, 1 \%$ Triton $\mathrm{X}-100,50 \mathrm{mM} \mathrm{MgCl}_{2}, 1 \mathrm{mM}$ Phenylmethylsulfonyl fluoride (PMSF), $2 \mathrm{mM}$ sodium orthovanadate, protease inhibitor cocktail (Set III, Calbiochem, Cat. No. 539134, La Jolla, CA, USA). A commercial kit (DC Protein Assay, Catalog 500-0116, Bio-Rad, Hercules, CA, USA) was used to determine total protein content. Forty $\mu \mathrm{g}$ of the sample were loaded in different lanes of an $8 \%$ SDSpolyacrylamide gel and subjected to electrophoresis. Afterwards, proteins were transferred to a nitrocellulose membrane and blocked with $5 \%$ non fat dry milk in TBS-Tween (Tween 20, $0.1 \%$ ) for $1.5 \mathrm{~h}$, at room 
temperature. Membranes were incubated overnight at $4{ }^{\circ} \mathrm{C}$ with anti-phospho- MYPT1 (1:500, Thr696, rabbit polyclonal antibody, Cat. 07-251, Millipore, CA, USA). Afterwards, membranes were incubated with a HRP conjugated goat anti-rabbit IgG secondary antibody (1:1000, Cat. 12-348, Millipore, CA, USA), incubated during $1 \mathrm{~h}$, at $37^{\circ} \mathrm{C}$. Immunoblots were developed using an enhanced chemiluminescent reactant (Super Signal West Femto Maximum Sensitivity Sustrate, Cat. 34096, Thermo Scientific, Rockford, IL, USA). PhosphoMYPT1 immunoblots were analyzed by densitometry using a Molecular Imaging ChemiDoc XRS (Bio-Rad, Hercules, CA, USA). Mouse monoclonal $\alpha$-actin antibody (1:1000, Cat. A5228, Sigma Chem. Co., St. Louis, MO, USA) was blotted as a control for protein load; membranes were incubated with a horseradish peroxidase-conjugated sheep anti-mouse IgG secondary antibody (1:2000, Cat. NA9310V, Amersham, Buckinghamshire, UK).

\section{Drugs}

Nidefipine, (+)-(R)-trans-4-(1-aminoethyl)-N-(4pyridyl) cyclohexane carboxamide (Y-27632) and methyl- $\beta$-cyclodextrin were all purchased from Sigma-Aldrich.

\section{Statistical analysis}

Differences in responses of bovine tracheal smooth muscle strips to $\mathrm{KCl}$ were evaluated through paired Student's $t$ test. For Western blot analysis we used non paired Student $t$ test and when more than two groups were evaluated, one-way analysis of variance followed by Dunnett's test. Statistical significance was set at twotailed $\mathrm{p}<0.05$. Data are expressed in the text and illustrations as mean $\pm \mathrm{SEM}$, and $\mathrm{n}$ represents the number of animals used.

\section{Results}

We confirmed an earlier finding (Sommer et al. 2009) that airway smooth muscle responses to $60 \mathrm{mM}$ $\mathrm{KCl}$ were reduced by incubation with $\mathrm{M} \beta \mathrm{CD}$ (Fig. 1A, $30.22 \pm 7.02 \%, n=6$ ). When tissues were incubated with $\mathrm{M} \beta \mathrm{CD}$ during $3 \mathrm{~h}$, nifedipine almost completely relaxed the $\mathrm{KCl}$-induced contraction (Fig. 1B,C). Contrastingly, time control showed no differences in the contractile response to $\mathrm{KCl}(6.37 \pm 0.45$ vs $6.19 \pm 0.52 \mathrm{~g}, \mathrm{n}=5)$.
A

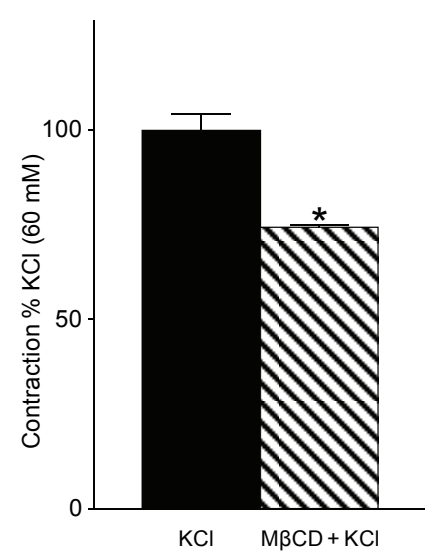

B

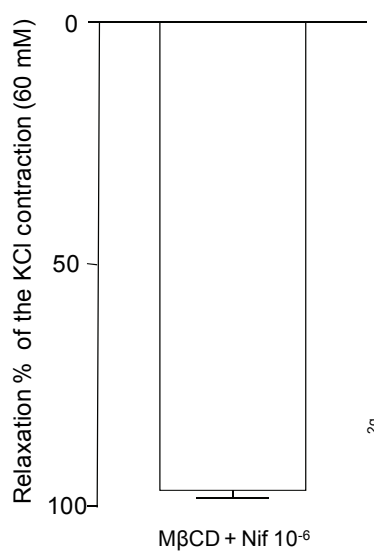

$M \beta C D+N$ if $10^{-6}$

ROCK inhibition with $10 \mu \mathrm{M} \quad \mathrm{Y}-27632$ significantly diminished the $\mathrm{KCl}$-induced contraction (Fig. 2A, 26.34 $\pm 3.70 \%, n=6$ ). No additive effect among $\mathrm{M} \beta \mathrm{CD}$ and $\mathrm{Y}-27632$ on $\mathrm{KCl}$-induced contraction was found $(38.43 \pm 7.12 \%, \mathrm{n}=8)$. When $1 \mu \mathrm{M}$ nifedipine was added during the plateau of the contraction induced by $\mathrm{KCl}$, we observed a partial relaxation of about $82 \%$. The addition of $\mathrm{Y}-27632$ produced an additional relaxation $(\sim 12 \%)$ which almost reached the resting basal level (Fig. 2B). In those experiments were Y-27632 was added first to a $\mathrm{KCl}$ precontracted tissue, we observed

Fig. 1. Effect of methyl- $\beta$ cyclodextrin (MBCD) and nifedipine (Nif) on $\mathrm{KCl}$ stimulated tissues. (A) Black bar represents $\mathrm{KCl}(60 \mathrm{mM})$ before $M B C D$. Crossed lined bar represents $\mathrm{KCl}$ induced contraction after $M \beta C D(40 \mathrm{mM}, 3 \mathrm{~h}$, $\mathrm{n}=6$ ) (B) Open bar represents relaxation induced by Nif $(1 \mu \mathrm{M})$ on $\mathrm{KCl}$ stimulated bovine tracheal smooth muscle previously incubated with $M B C D \quad(40 \mathrm{mM}, 3 \mathrm{~h}, \mathrm{n}=4)$. (C) Representative trace of this experimental protocol. W: wash. ${ }^{*} p<0.05$, using paired Student $t$ test. a relaxation about $\sim 45 \%$ and the remaining contraction was abolished by nifedipine ( $\sim 55 \%$, Fig. $2 \mathrm{C})$. When we compared each antagonist under the different experimental conditions, we found that they (nifedipine vs nifedipine, $\mathrm{p}=0.05$; and $\mathrm{Y}-27632$ vs $\mathrm{Y}-27632 \mathrm{p}=0.025$ ) were statistically different (Fig 2B,C). One possible explanation to these results would be that ROCK activation is sensitive to intracellular $\mathrm{Ca}^{2+}$ concentration. Therefore, when the $\mathrm{Ca}^{2+}$ entrance is not diminished by nifedipine, the amount of activated ROCK is more efficiently inhibited by $10 \mu \mathrm{M}$ Y-27632. 


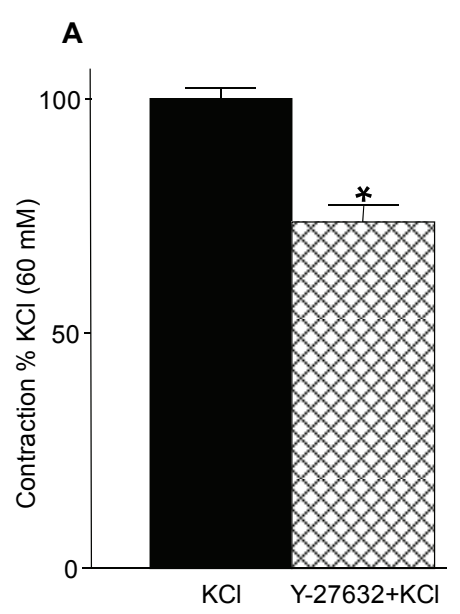

B

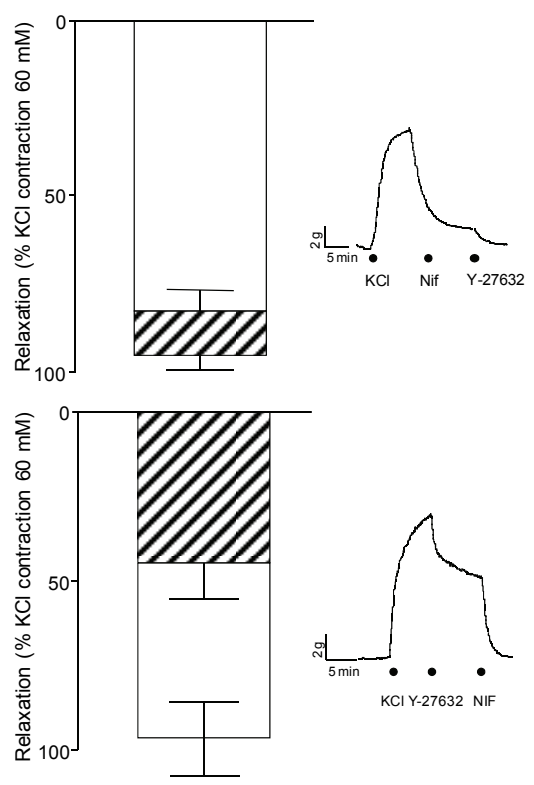

Fig. 2. Effect of $\mathrm{Y}-27632$ and nifedipine on $\mathrm{KCl}$ induced contraction. (A) Black bar shows $\mathrm{KCl}$ $(60 \mathrm{mM})$ contraction before incubation with Y-27632 (10 $\mu \mathrm{M}, \mathrm{n}=6$, Rho kinase inhibitor). Crossed lined bar depicts $\mathrm{KCl}$ contraction after the incubation with Y-27632. (B) Open bar illustrates the relaxation induced by nifedipine (Nif, $1 \mu \mathrm{M}, \mathrm{n}=6$ ) in control tissues. Crossed patterned rectangle indicates the further relaxation induced on the same preparation by the addition of Y-27632. (C) Crossed patterned bar shows the $\mathrm{Y}-27632$ induced relaxation and the open bar, the nifedipine response. Right, a representative trace of the experiments graphed in (B) and (C) is shown. *, significant at $\mathrm{p}<0.01$ by paired Student $t$ test.
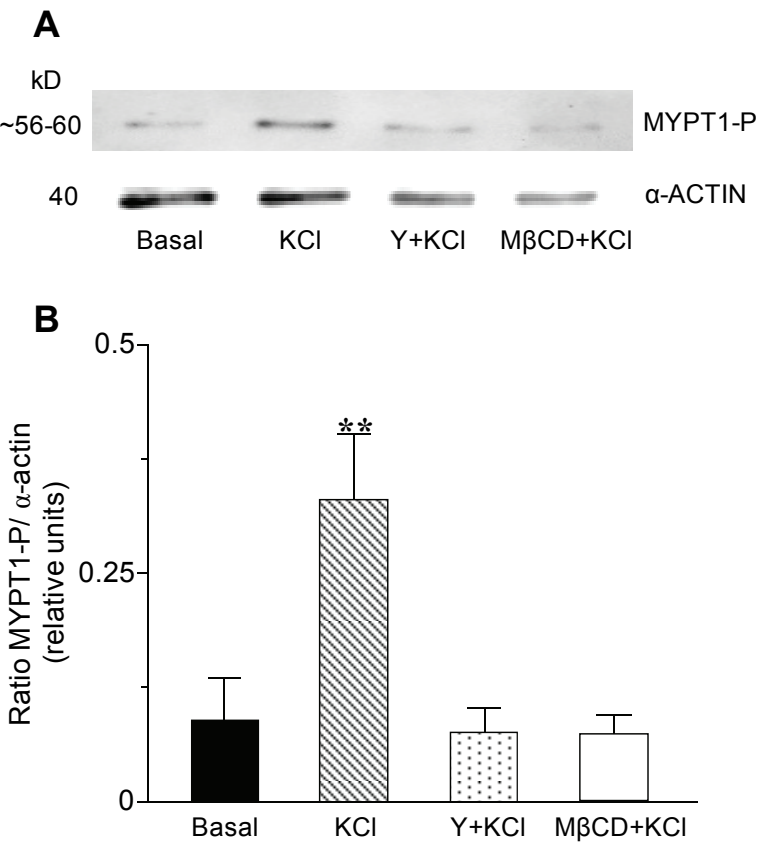

Fig. 3. ROCK activity through MYPT1 phosphorylation (MYPT1-P) assay in bovine tracheal smooth muscle. (A) Representative western blots for MYPT1-P (basal, $n=4$ ) induced by $\mathrm{KCl}$ stimulation $(60 \mathrm{mM}, \mathrm{n}=3)$ by $\mathrm{Y}-27632(\mathrm{Y}, 10 \mu \mathrm{M}, \mathrm{n}=3)$ and $\mathrm{M} \beta C D$ $(40 \mathrm{mM}, 3 \mathrm{~h}, \mathrm{n}=4)$. (B) Densitometry analysis showing that $\mathrm{KCl}$ stimulation significantly increased MYPT1-P and its diminution by Y-27632 or MBCD. ${ }^{* *} p<0.01$ by analysis of variance and Dunnett tests.

In bovine tracheal smooth muscle, ROCK activity was significantly increased by $\mathrm{KCl}$ stimulation $(\mathrm{p}<0.01)$; this augmentation was annulled when tissues were pre-incubated with Y-27632 or M $\beta C D$ (Fig. 3). This last result points out that caveolae are required for the proper activation of the ROCK component.

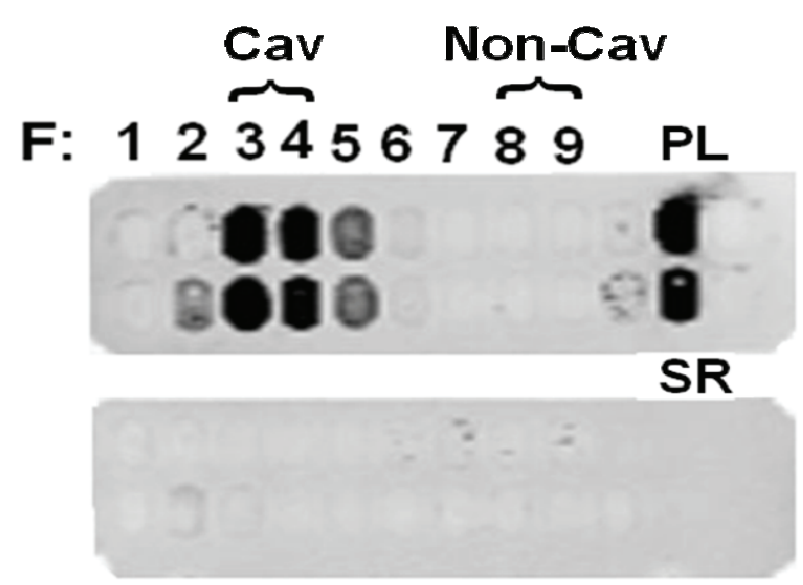

Fig. 4. Dot blot from bovine tracheal smooth muscle membrane fractions to identify caveolar ganglioside GM1, through FITC coupled cholera toxin B. Fractions 3-4 were recognized as caveolar (Cav) fractions and 8-9 as non-caveolar (Non-Cav). $\mathrm{F}$ - membrane fraction from gradient top (1) to bottom (9). $\mathrm{PL}$ - plasmalemma. SR - sarcoplasmic reticulum. Top blot shows results in duplicate for fractionated $\mathrm{PL}$, while lower blot shows negative results from SR only. The $n$ values for these experiments were 3 .

Dot blot results showed that GM1 (a characteristic caveolar gangleoside) was mainly present in membrane fractions 3-4 from bovine tracheal smooth muscle, corresponding to caveolar regions (Cav). No staining was seen in non-caveolar (Non-Cav) fractions 6-9. We corroborated that this GM1 was not present in the sarcoplasmic reticulum from the same preparation (Fig. 4).

Western blot from pooled fractions (3-4: caveolar; 8-9: non-caveolar) showed that $\mathrm{Ca}_{\mathrm{v}} 1.2$ and ROCK1 are only present in non-caveolar membrane 
fractions, while Cav-1 is located exclusively to the caveolar fraction (Fig. 5A). Two bands were recognized by the monoclonal antibody corresponding to isoforms Cav- $1 \alpha$ at $24 \mathrm{kD}$ and Cav-1 $\beta$ at $21 \mathrm{kD}$ (Fujimoto et al. 2000, Krasteva et al. 2006). Treatment with M $\beta C D$ did not modify the non-caveolar localization of the $\mathrm{Ca}_{\mathrm{v}} 1.2$ nor ROCK1, but transferred Cav-1 from caveolar fraction to non-caveolar fractions as reported previously (Sommer et al. 2009). These findings were confirmed by densitometry analysis of the data (Fig. 5B,C).

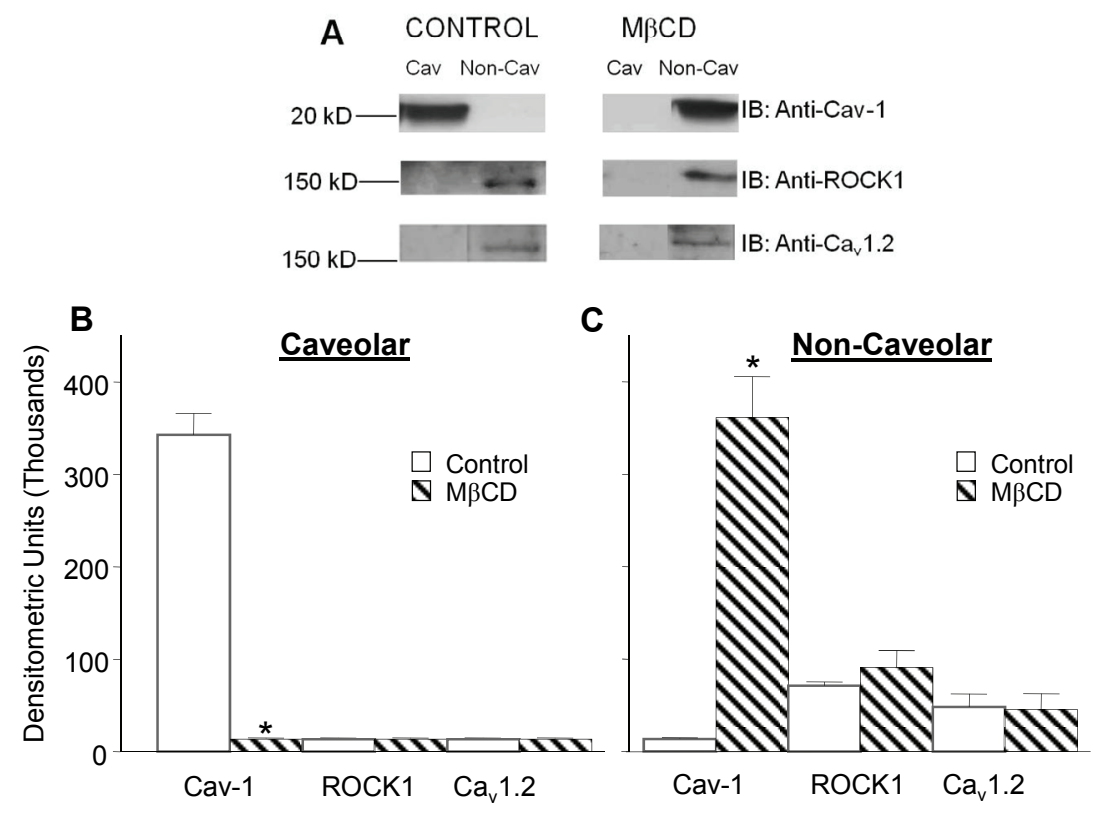

Fig. 5. Densitometry data from Western blots ( $n=3$, each) for Cav- 1, ROCK1 and voltage dependent $\mathrm{Ca}^{2+}$ channels $\left(\mathrm{Ca}_{v} 1.2\right)$, in caveolar (Cav) and non-caveolar (Non-Cav) membrane fractions from control and $M B C D$ treated bovine tracheal smooth muscles. (A) Representative western blots for caveolin-1 (Cav-1), Rho kinase 1 (ROCK1) and for $\mathrm{Ca}_{\mathrm{v}} 1.2$. (B) Densitometry data showed significances: $* p<0.01$ with respect to its control group. Non paired Student $t$ tests were used. IB $=$ immunoblot.
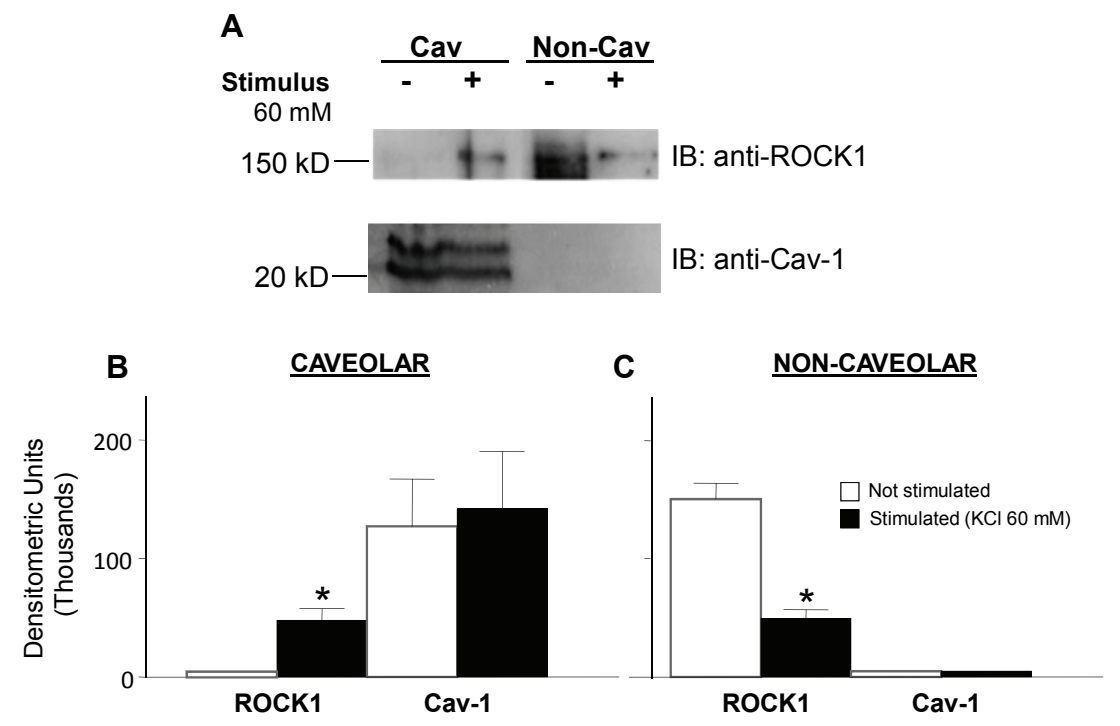

Fig. 6. Densitometry data from Western blots for ROCK1 and Cav-1 ( $n=3$, each) in caveolar (Cav) and non-caveolar (Non-Cav) fractions from plasmalemma obtained from $\mathrm{KCl}$ stimulated and not stimulated bovine tracheal smooth muscle. (A) Representative western blots for Rho kinase 1 (ROCK1) and for caveolin-1 (Cav-1) from KCl stimulated $(+)$ and not stimulated (-) tissues. (B) Densitometry analysis showing that, in tissues stimulated with $\mathrm{KCl}$, ROCK1 redistributed from non-caveolar to caveolar fractions. Cav-1 location was not modified by the $\mathrm{KCl}$ stimulus. Non paired Student $t$ tests were used. $* \mathrm{p}<0.05$ with respect to its not stimulated group.

In not stimulated tissues ROCK1 was present only in non-caveolar membrane fractions, while, in membrane preparation from $\mathrm{KCl}$ stimulated tissues, ROCK1 was found in both caveolar and non-caveolar fractions. Cav-1 did not modify its localization after $\mathrm{KCl}$ stimulation (Fig. 6A). Further analysis of the data confirms that ROCK1 moves from non-caveolar to caveolar membrane fraction when tissues were stimulated with $\mathrm{KCl}$ (Fig. 6B,C).

\section{Discussion}

In this manuscript we state that, in bovine airway smooth muscle, $\mathrm{KCl}$ stimulation activates RhoA/ROCK pathway and promotes ROCK1 translocation to caveolar regions. Although the detailed mechanisms of such translocation remain to be elucidated, it could be that this isotype is partially responsible for the $\mathrm{KCl}$-induced contraction. 
Airway smooth muscle excitation-contraction processes remain not fully understood. Our study illustrates this for the $\mathrm{KCl}$-induced contraction. Membrane depolarization through relatively high $\mathrm{KCl}$ concentrations has routinely been used to trigger the opening of voltage dependent $\mathrm{Ca}^{2+}$ channels and the consequent influx of extracellular $\mathrm{Ca}^{2+}$ (Janssen et al. 1999, Flores-Soto et al. 2011). This increase in intracellular $\mathrm{Ca}^{2+}$ concentration was long thought to be the main reason for airway smooth muscle contraction under these conditions. However, increasing evidences suggest that, in airway smooth muscle, the RhoA/ROCK signaling pathway is definitely involved in $\mathrm{KCl}$ induced contraction (Janssen et al. 2004, 2012). On the other hand, it has been shown in uterine and airway smooth muscle that stimuli that activate RhoA/ROCK augment both molecules translocation from the cytosol to the membrane (Taggart et al. 1999, Chiba and Misawa 2004). Later on, it was reported that these molecules move to a specific membrane compartment called caveolae (Taggart et al. 2000, Urban et al. 2003, Hunter and Dixon 2006). Recently, in mice aortic tissues, it was reported that RhoA/ROCK moves from caveolar to non-caveolar regions after stimulation with 5-HT (Nuno et al. 2012). These findings demonstrated that both molecules might move not only from the cytosol to the membrane, but from one membrane domain to another. In airway smooth muscle, it has been shown that, $\mathrm{KCl}$ induced $\mathrm{Ca}^{2+}$ influx promotes RhoA/ROCK activation, although membrane potential could be also involved (Liu et al. 2005).

As we reported previously (Sommer et al. 2009), the $\mathrm{KCl}$ induced contraction in ASM partially depends on ROCK while caveolae remain intact. These membrane structures have been widely studied and, while they are indispensable for a proper $\mathrm{KCl}$-induced contraction in ASM we now report that ROCK's inhibition through $\mathrm{Y}-27632$, diminishes $\mathrm{KCl}$ induced contractions to the same extent as M $\beta C D$ (both approximately $30 \%$ of the $\mathrm{KCl}$ contraction, Fig. 1A). Our physiological data also demonstrated that, in M $\beta C D$ treated tissues, the ROCK component completely disappeared, leaving only the response to $\mathrm{Ca}_{\mathrm{v}} 1.2$ (Fig. $1 \mathrm{C}$ ). These results show that the $\mathrm{KCl}$ contraction is composed by the activation of $\mathrm{Ca}_{\mathrm{v}} 1.2$ and RhoA/ROCK signaling pathway and the latest is dependent of the caveolar integrity. We confirm that $\mathrm{KCl}$ induced ROCK activation and this response was abolished by Y-27632 and M $\beta C D$ (Fig. 3). This drug also modified the membrane localization of Cav-1, transferring it from caveolar to non caveolar membrane fractions (Fig. 4A) as previously reported (Sommer et al. 2009). These findings might explain the disappearance of ROCK participation during the $\mathrm{KCl}$ induced contraction when caveolae were disrupted.

To clarify further if ROCK's isotype 1 is implicated in the caveolar-dependent component of the $\mathrm{KCl}$ induced contraction, we performed western blots from membrane fractions (caveolar and non-caveolar, Fig. 5) from stimulated and not stimulated tracheal smooth muscle preparations. ROCK1 localization in the cytosol as well as in the cell membrane was already known (Sommer et al. 2009), but, at that time the precise membrane site where ROCK1 was located was not defined in an isolated plasmalemma. Our present results showed, in isolated airway smooth muscle plasma membrane, that ROCK1 can be found at the non-caveolar fractions in not stimulated tissues, and that it translocates to caveolar fractions upon $\mathrm{KCl}$ stimulation. It has been shown that in airway smooth muscle, $\mathrm{KCl}$ induced $\mathrm{Ca}^{2+}$ influx promotes RhoA/ROCK activation, although membrane potential could be also involved (Liu et al. 2005). Thus, ROCK1 translocation from non-caveolar to caveolar membrane fractions upon $\mathrm{KCl}$ stimulation could be related to $\mathrm{Ca}^{2+}$ influx and/or membrane depolarization. This result sharply contrasts with the findings in mice aortic tissues (Nuno et al. 2012), where the ROCK component of the $\mathrm{KCl}$ induced contraction is caveolaeindependent. Because ROCK's predominant isotype in vascular smooth muscle is type 2, physiological and molecular differences among this tissue and airway smooth muscle could be due to this fact. Probably, ROCK's different isotypes imply different physiological responses. Further investigation in ASM is needed to clarify whether ROCK1 also translocates to caveolar regions after its activation through other pathway activating stimuli (i.e. histamine, 5-HT, etc.).

Additionally, we found that, under our experimental conditions, $\mathrm{Ca}_{\mathrm{v}} 1.2$ is not localized in caveolar membrane fractions, but is the sole membranal structure responsible for $\mathrm{KCl}$ induced contraction when caveolae were disrupted with $\mathrm{M} \beta \mathrm{CD}$. A possible explanation to this finding is that $\mathrm{Ca}_{\mathrm{v}} 1.2$ might move from non caveolar to caveolar domains as ROCK1 after $\mathrm{KCl}$ stimulation.

In conclusion, airway smooth muscle stimulation with $\mathrm{KCl}$ probably promotes ROCK 1 traslocation from non-caveolar to caveolar regions. This translocation seems to be indispensable for a complete $\mathrm{KCl}$-induced contraction; when caveolae are disrupted through $\mathrm{M} \beta \mathrm{CD}$, a $\mathrm{Ca}_{\mathrm{v}} 1.2$-dependent partial contraction remains. 


\section{Conflict of Interest}

There is no conflict of interest.

\section{Acknowledgements}

This study was supported by the National Institute of Respiratory Diseases.

\section{References}

BABIYCHUK EB, SMITH RD, BURDYGA T, BABIYCHUK VS, WRAY S, DRAEGER A: Membrane cholesterol regulates smooth muscle phasic contraction. J Membr Biol 198: 95-101, 2004.

BHATNAGAR A, SHEFFLER DJ, KROEZE WK, COMPTON-TOTH B, ROTH BL: Caveolin-1 interacts with $5-\mathrm{HT}_{2 \mathrm{~A}}$ serotonin receptors and profoundly modulates the signaling of selected $\mathrm{Ga}_{\mathrm{q}}$-coupled protein receptors. J Biol Chem 279: 34614-34623, 2004.

BLANK N, GABLER C, SCHILLER M, KRIEGEL M, KALDEN JR, LORENZ HM: A fast, simple and sensitive method for the detection and quantification of detergent-resistant membranes. J Immunol Methods 271: 25-35, 2002.

CHIBA Y, MISAWA M: The role of RhoA-mediated $\mathrm{Ca}^{2+}$ sensitization of bronchial smooth muscle contraction in airway hyperresponsiveness. J Smooth Muscle Res 40: 155-167, 2004.

CHO WJ, DANIEL EE: Proteins of interstitial cells of Cajal and intestinal smooth muscle, colocalized with caveolin-1. Am J Physiol Gastrointest Liver Physiol 288: G571-G585, 2005.

DARBY PJ, KWAN CY, DANIEL EE: Caveolae from canine airway smooth muscle contain the necessary components for a role in $\mathrm{Ca}^{2+}$ handling. Am J Physiol Lung Cell Mol Physiol 279: L1226-L1235, 2000.

DREJA K, VOLDSTEDLUND M, VINTEN J, TRANUM-JENSEN J, HELLSTRAND P, SWÄRD K: Cholesterol depletion disrupts caveolae and differentially impairs agonist-induced arterial contraction. Arterioscler Thromb Vasc Biol 22: 1267-1272, 2002.

FLORES-SOTO E, CARBAJAL V, REYES-GARCÍA J, GARCÍA-HERNÁNDEZ LM, FIGUEROA A, CHECA M, BARAJAS-LÓPEZ C, MONTAÑO LM: In airways ATP refills sarcoplasmic reticulum via P2X smooth muscle receptors and induces contraction through P2Y epithelial receptors. Pflugers Arch 461: 261-275, 2011.

FUJIMOTO T, KOGO H, NOMURA R, UNE T: Isoforms of caveolin-1 and caveolar structure. J Cell Sci 113: 3509$3517,2000$.

HUNTER I, NIXON GF: Spatial compartmentalization of tumor necrosis factor (TNF) receptor 1-dependent signaling pathways in human airway smooth muscle cells. Lipid rafts are essential for TNF-alpha-mediated activation of RhoA but dispensable for the activation of the NF-kappaB and MAPK pathways. J Biol Chem 281: 3470534715, 2006.

JANSSEN LJ: Airway smooth muscle electrophysiology in a state of flux? Am J Physiol Lung Cell Mol Physiol 302: L730-L732, 2012.

JANSSEN LJ, BETTI PA, NETHERTON SJ, WALTERS DK: Superficial buffer barrier and preferentially directed release of $\mathrm{Ca}^{2+}$ in canine airway smooth muscle. Am J Physiol 276: L744-L753, 1999.

JANSSEN LJ, TAZZEO T, ZUO J, PERTENS E, KESHAVJEE S: KCl evokes contraction of airway smooth muscle via activation of RhoA and Rho-kinase. Am J Physiol Lung Cell Mol Physiol 287: L852-L858, 2004.

KRASTEVA G, PFEIL U, DRAB M, KUMMER W, KÖNIG P: Caveolin-1 and -2 in airway epithelium: expression and in situ association as detected by FRET-CLSM. Respir Res 7: 108, 2006.

LEUNG T, MANSER E, TAN L, LIM L: A novel serine/threonine kinase binding the Ras-related RhoA GTPase which translocates the kinase to peripheral membranes. J Biol Chem 270: 29051-29054, 1995.

LIU C, ZUO J, PERTENS E, HELLI PB, JANSSEN LJ: Regulation of Rho/ROCK signaling in airway smooth muscle by membrane potential and [ $\left.\mathrm{Ca}^{2+}\right]$ i. Am J Physiol Lung Cell Mol Physiol 289: L574-L582, 2005.

LÖHN M, FURSTENAU M, SAGACH V, ELGER M, SCHULZE W, LUFT FC, HALLER H, GOLLASCH M: Ignition of calcium sparks in arterial and cardiac muscle through caveolae. Circ Res 87: 1034-1039, 2000.

MATSUI T, AMANO M, YAMAMOTO T, CHIHARA K, NAKAFUKU M, ITO M, NAKANO T, OKAWA K, IWAMATSU A, KAIBUCHI K: Rho-associated kinase, a novel serine/threonine kinase, as a putative target for small GTP binding protein Rho. EMBO J 15: 2208-2216, 1996. 
MITA M, YANAGIHARA H, HISHINUMA S, SAITO M, WALSH MP: Membrane depolarization-induced contraction of rat caudal arterial smooth muscle involves Rho-associated kinase. Biochem J 364: 431-440, 2002.

NOMA K, OYAMA N, LIAO JK: Physiological role of ROCKs in the cardiovascular system. Am J Physiol Cell Physiol 290: C661-C668, 2006.

NUNO DW, ENGLAND SK, LAMPING KJ: RhoA localization with caveolin-1 regulates vascular contraction to serotonin. Am J Physiol Regul Integr Comp Physiol 303: R959-R967, 2012.

PARTON RG: Ultrastructural localization of gangliosides; GM1 is concentrated in caveolae. J Histochem Cytochem $\mathbf{4 2}$ : 155-166, 1994.

SOMLYO AP, SOMLYO AV: $\mathrm{Ca}^{2+}$ sensitivity of smooth muscle and nonmuscle myosin II: modulated by $\mathrm{G}$ proteins, kinases, and myosin phosphatase. Physiol Rev 83: 1325-1358, 2003.

SOMMER B, MONTANO LM, CARBAJAL V, FLORES-SOTO E, ORTEGA A, RAMÍREZ-OSEGUERA R, IRLES C, EL-YAZBI AF, CHO WJ, DANIEL EE: Extraction of membrane cholesterol disrupts caveolae and impairs serotonergic $\left(5-\mathrm{HT}_{2 \mathrm{~A}}\right)$ and histaminergic $\left(\mathrm{H}_{1}\right)$ responses in bovine airway smooth muscle: role of Rho-kinase. Can J Physiol Pharmacol 87: 180-195, 2009.

TAGGART MJ, LEE YH, MORGAN KG: Cellular redistribution of PKC $\alpha$, rhoA, and ROK $\alpha$ following smooth muscle agonist stimulation. Exp Cell Res 251: 92-101, 1999.

TAGGART MJ, LEAVIS P, FERON O, MORGAN KG: Inhibition of PKC $\alpha$ and rhoA translocation in differentiated smooth muscle by a caveolin scaffolding domain peptide. Exp Cell Res 258: 72-81, 2000.

URBAN NH, BERG KM, RATZ PH: $\mathrm{K}^{+}$depolarization induces RhoA kinase translocation to caveolae and $\mathrm{Ca}^{2+}$ sensitization of arterial muscle. Am J Physiol Cell Physiol 285: C1377-C1385, 2003. 